\title{
Neck Location on the Outer Convexity is a Predictor of Incomplete Occlusion in Treatment with the Pipeline Embolization Device: Clinical and Angiographic Outcomes
}

\author{
(D)T. Sunohara, (D) H. Imamura, (D) M. Goto, (D) Rukumitsu, (D) S. Matsumoto, (D) N. Fukui, (D). Oomura, (D)T. Akiyama, \\ (D) T. Fukuda, (D). Go, DS. Kajiura, (D) M. Shigeyasu, (D) K. Asakura, (DR. Horii, (D) C. Sakai, and (D). Sakai
}

\begin{abstract}
BACKGROUND AND PURPOSE: With the increasing use of the Pipeline Embolization Device for the treatment of aneurysms, predictors of clinical and angiographic outcomes are needed. This study aimed to identify predictors of incomplete occlusion at last angiographic follow-up.

MATERIALS AND METHODS: In our retrospective, single-center cohort study, 105 ICA aneurysms in 89 subjects were treated with Pipeline Embolization Devices. Patients were followed per standardized protocol. Clinical and angiographic outcomes were analyzed. We introduced a new morphologic classification based on the included angle of the parent artery against the neck location: outer convexity type (included angle, $\left.<160^{\circ}\right)$, inner convexity type (included angle, $\left.>200^{\circ}\right)$, and lateral wall type $\left(160^{\circ} \leq\right.$ included angle $\left.\leq 200^{\circ}\right)$. This classification reflects the metal coverage rate and flow dynamics.

RESULTS: Imaging data were acquired in $95.3 \%$ of aneurysms persistent at 6 months. Complete occlusion was achieved in $70.5 \%$, and incomplete occlusion, in $29.5 \%$ at last follow-up. Multivariable regression analysis revealed that 60 years of age or older (OR, 5.70; $P=.001)$, aneurysms with the branching artery from the dome (OR, 10.56; $P=.002)$, fusiform aneurysms (OR, 10.2; $P=.009)$, and outer convexitytype saccular aneurysms (versus inner convexity type: OR, 30.3; $P<.001$; versus lateral wall type: OR, 9.71; $P=.001$ ) were independently associated with a higher rate of incomplete occlusion at the last follow-up. No permanent neurologic deficits or rupture were observed in the follow-up period.
\end{abstract}

CONCLUSIONS: The aneurysm neck located on the outer convexity is a new, incomplete occlusion predictor, joining older age, fusiform aneurysms, and aneurysms with the branching artery from the dome. No permanent neurologic deficits or rupture was observed in the follow-up, even with incomplete occlusion.

ABBREVIATIONS: $\mathrm{MCR}=$ metal coverage ratio; $\mathrm{PED}=$ Pipeline Embolization Device

$\mathbf{F}$ ow-diversion stents with the Pipeline Embolization Device (PED; Medtronic) were first reported in 2008. ${ }^{1}$ Since then, multiple trials ${ }^{2-6}$ and retrospective studies ${ }^{3,7,8}$ have reported the safety and efficacy of the PED in the treatment of intracranial aneurysms. Long-term follow-up data showed a $95.2 \%$ occlusion rate at 5 years after treatment ${ }^{3,8}$ and no evidence of recanalization of previously occluded aneurysms. ${ }^{3}$ Angiographic and clinical long-term follow-up data are important because incomplete occlusion leads to retreatment or rerupture in coil embolization. ${ }^{9}$

Several factors such as age, sex, smoking, fusiform-type aneurysms, small aspect ratios, and dome-neck ratios have been reported

Received June 10, 2020; accepted after revision August 11.

From the Department of Neurosurgery, Kobe City Medical Center General Hospital, Kobe, Japan.

Please address correspondence to Tadashi Sunohara, MD, PhD, Kobe City Medical Center General Hospital, Department of Neurosurgery, 2-1-1 Minami-cho, Minatojima, Chuo-ku, Kobe, 650-0047, Japan; e-mail: tadashi_sunohara@kcho.jp

Indicates article with supplemental online tables.

http://dx.doi.org/10.3174/ajnr.A6859 to be predictors of incomplete or complete occlusion. ${ }^{10-17}$ However, there is debate about outcomes when using these factors because of limited analysis of the confounding factors. Moreover, the follow-up imaging rate of incomplete occlusion is sometimes insufficient (around $50 \%$ at 6 months). ${ }^{1}$ Additionally, the same morphologic indices used in coil embolization were used in previous PED studies, even though the 2 methods are different in their treatment mechanism for aneurysms. The metal coverage ratio (MCR) ${ }^{18-20}$ is an important metric of PED treatment.

Although the MCR correlates with the occlusion rate, ${ }^{19}$ it is calculated after treatment and additional work-up is needed to acquire it. Therefore, in this study, we introduced a new classification based on the included angle of the parent artery against the neck location for the aneurysm, which can be measured before the PED treatment and complements the MCR: outer convexity type, inner convexity type, and lateral wall type. In addition, we clarified factors, including our new classification, affecting incomplete occlusion and clinical 
outcome in PED treatment, on the basis of data with a high follow-up rate.

\section{MATERIALS AND METHODS Study Design}

A retrospective analysis of consecutive aneurysms treated with PED placement between July 2015 and July 2019 at a single institution was performed. The inclusion criteria consisted of all adult patients with intracranial unruptured aneurysms treated with the PED who had undergone angiographic follow-up. All aneurysm morphologies (ie, saccular, fusiform, and so forth) and intracranial locations were included. Institutional review board approval was obtained at the center before commencement of the study. Informed consent was obtained in the form of an opt-out on the Web site. Those who opted out were excluded from the study (0 patients). We collected the following information: patient demographics, aneurysm and PED characteristics, procedural complications, and angiographic and functional outcomes.

\section{Procedural Details}

Patients received aspirin, $100 \mathrm{mg}$, and clopidogrel, $75 \mathrm{mg}$ daily, for 10-14 days before the intervention. Platelet function testing was routinely performed with the VerifyNow P2Y12 assay and the VerifyNow Aspirin assay (Accumetrics) on the day before the procedure. Clopidogrel nonresponders were identified on the basis of established cutoff values of $>220$, and aspirin nonresponders, of $>550$. If a patient was identified as a clopidogrel responder, the clopidogrel was continued. If a patient was identified as a clopidogrel nonresponder, the treatment was switched to prasugrel, $3.5 \mathrm{mg}$ daily, with a 1-time loading dose of $20 \mathrm{mg}$ administered 24 hours before the procedure. If a patient was identified as an aspirin nonresponder, the daily dose of aspirin was increased to $200 \mathrm{mg}$. Dualantiplatelet therapy was continued for at least 6 months after the procedure, and single-antiplatelet therapy was continued indefinitely thereafter.

Patients were under general anesthesia, and all patients were anticoagulated with heparin throughout the procedure. The $8 \mathrm{~F}$ guiding catheter, 5F Navien (Medtronic) distal-access catheter, and a Marksman (Medtronic) microcatheter were used in a coaxial system as a standard combination at the institute.

\section{Angiographic Outcome}

Angiographic outcome was assessed with DSA or MRA on the basis of the follow-up protocol. At 6 months after the procedure, all patients and aneurysms were assessed with DSA. If aneurysms were completely occluded at DSA, a follow-up assessment was performed with MRA 6-12 months thereafter. In the case of partial occlusion at DSA, follow-up DSA was performed 3-6 months later. In the case of nearly complete occlusion at DSA, follow-up DSA or MRA was performed 3-6 months later at the discretion of the operator.

Aneurysm occlusion on the follow-up DSA was assessed by trained interventionalists. Follow-up MRA was assessed by a radiologist blinded to the clinical history and a trained interventionalist. Occlusion was categorized as complete occlusion (100\%), nearcomplete occlusion (90\%-99\%), and partial occlusion (<90\%) at DSA or MRA. Both near-complete and partial occlusion were collectively defined as incomplete occlusion.

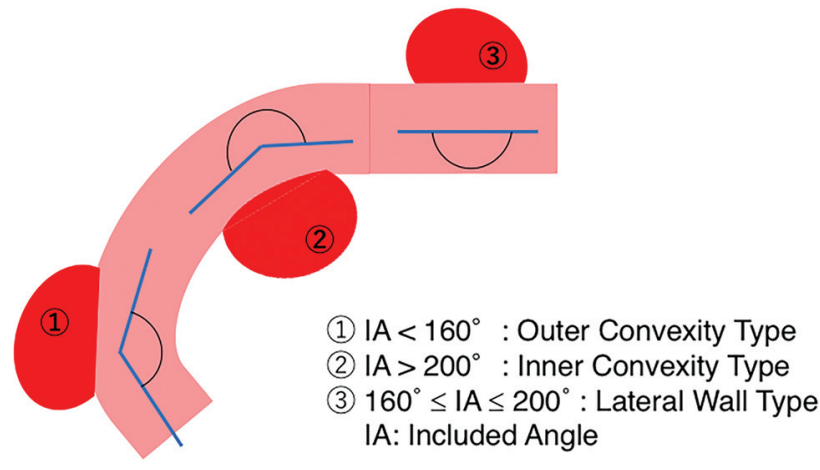

FIGURE. Classification of saccular aneurysms.

\section{Classification of Saccular Aneurysms}

Saccular aneurysms were classified into 3 subtypes based on the included angle of the parent artery against the neck location. The included angle is the angle formed by the arc of the internal carotid artery against the aneurysm neck location. The angle was measured by 2 workstations (Xtra Vision R1.3.2, Philips Healthcare, and SYNAPSE VINCENT V5.2, Fujifilm), and the aneurysm was categorized as outer convexity (included angle, $<160^{\circ}$;), inner convexity (included angle, $\left.>200^{\circ}\right)$, or lateral wall $\left(160^{\circ} \leq\right.$ included angle $\leq 200^{\circ}$ ) (Figure).

\section{Clinical Outcome}

Functional outcome was assessed with the mRS at each follow-up by the neurosurgeon and interventionalist.

\section{Statistical Analysis}

Statistical analysis was performed with JMP software, Version 10 (SAS Institute). In the univariable analysis, variables were compared among groups with the nonparametric test for continuous variables and the $\chi^{2}$ test for categoric variables to identify predictors of incomplete occlusion and bad neurologic outcome. Statistical significance was defined as $P<.05$. Multivariable logistic regression was performed on candidate predictor variables to identify variables independently associated with incomplete occlusion and clinical outcome at the last angiographic follow-up after controlling for potential confounders.

\section{Baseline and Aneurysm Characteristics}

A total of 108 sequential aneurysms treated with PED placement at a single institution were identified. Of these, 105 (97.2\%) aneurysms treated by 91 PED procedures in 89 patients (median age, 58 years; female/male ratio, 4.9:1) had angiographic followup and were included in this study. All treatments were for unruptured aneurysms. Aneurysms were along the ICA. The locations and measurements are shown in Table 1. Aneurysms including the branching artery from the dome were present in $15.2 \%$. The morphologic types of saccular aneurysms were composed of the outer convexity type in $35.7 \%$, inner convexity type in $29.6 \%$, and lateral wall type in $34.7 \%$. Among patients, $28.6 \%$ exhibited symptoms from cranial nerve compression before treatment (Table 1). 
Table 1: Baseline characteristics of aneurysms and patient demographics

\begin{tabular}{lc}
\hline & Value \\
\hline Patients $(n=89)$ & \\
Age (yr) & \\
Median (range) & $58(20-88)$ \\
Sex & \\
Female & $74(83.1 \%)$ \\
Male & $15(16.9 \%)$ \\
Current smoking & $30(28.6 \%)$ \\
Pretreatment mRS & \\
0-2 & $89(100 \%)$ \\
$3-5$ & $0(0 \%)$ \\
Symptomatic cranial nerve compression & $26(28.6 \%)$ \\
Aneurysms ( $n=105)$ & \\
Measurements (mm) & \\
Median (range) & \\
Maximum diameter & $10.5(2-33)$ \\
Neck size of saccular aneurysms & $6.4(2-14)$ \\
Height of saccular aneurysms & $6.0(0.9-28)$ \\
Aneurysm type & \\
Saccular & $98(93.3 \%)$ \\
Fusiform & $7(6.7 \%)$ \\
Aneurysm location & \\
ICA petrous & \\
ICA cavernous & $4(3.8 \%)$ \\
ICA paraclinoid & $31(29.5 \%)$ \\
ICA Cl segment & $58(55.2 \%)$ \\
Branching artery from dome & $12(11.4 \%)$ \\
Multiple aneurysms & $16(15.2 \%)$ \\
Morphologic types of saccular aneurysm & $13(14.3 \%)$ \\
Outer convexity & \\
Inner convexity & $35(35.7 \%)$ \\
Lateral wall & $29(29.6 \%)$ \\
Procedures ( $n=91)$ & $34(34.7 \%)$ \\
No. of Pipelines & \\
1 & \\
2 & $90(98.9 \%)$ \\
\hline & $1(1.1 \%)$ \\
\hline
\end{tabular}

\section{Treatment Outcome}

The median length of the angiographic follow-up was 27 months (range, 9-60 months). All patients (89 patients, 105 aneurysms) had 6-month angiographic follow-up. Table 2 shows the occlusion rate at 6-months after treatment and at the last follow-up. The long-term imaging follow-up rate of patients with incomplete occlusion at 6-month DSA was $95.3 \%$ (41/43). The median length of the angiographic follow-up of patients with incomplete occlusion at 6-month DSA was 27.5 months (range, 10-54 months). An adjunctive coil was used in $33.3 \%$ of aneurysms, most of which were intradural aneurysms. Retreatment was performed in $5.5 \%$ of aneurysms and was exclusively endovascular. The mRS scores just after PED placement were $0-2$ in $94.4 \%$ of procedures and $3-5$ in $5.6 \%$ because of ischemic stroke or the worsening of cranial nerve compression. At the last follow-up, the mRS scores were improved in $18.0 \%$ of patients. Improvement included pre-existing cranial nerve compression symptoms or postprocedural symptomatic stroke. Symptomatic neurologic complications appeared in $7.7 \%$ of procedures. Symptomatic thromboembolic complications were encountered in $6.6 \%$ of procedures, and symptomatic hemorrhagic complications, in $0 \%$. In 1 case, a symptom of cranial nerve compression appeared after treatment because of a thrombosing aneurysm. In $37.0 \%$, cranial nerve compression was improved in the
Table 2: Outcome measures

\begin{tabular}{|c|c|}
\hline & Value \\
\hline \multicolumn{2}{|l|}{ Platelet function test } \\
\hline Yes & 89 (100\%) \\
\hline No & $0(0 \%)$ \\
\hline \multicolumn{2}{|l|}{ Clopidogrel responder } \\
\hline Yes & $66(74.2 \%)$ \\
\hline No & $23(25.8 \%)$ \\
\hline \multicolumn{2}{|l|}{ Angiographic outcome } \\
\hline \multicolumn{2}{|l|}{ Imaging follow-up } \\
\hline Median (range) (mo) & $27(9-60)$ \\
\hline Data availability & $89 / 92(96.7 \%)$ \\
\hline $\begin{array}{l}\text { Long-term imaging follow-up rate with } \\
\text { aneurysm persistent at } 6 \mathrm{mo}\end{array}$ & $41 / 43(95.3 \%)$ \\
\hline \multicolumn{2}{|l|}{ Occlusion rate at $6 \mathrm{mo}$} \\
\hline Complete (100\%) & $62(59.0 \%)$ \\
\hline Near-complete (90\%-99\%) & $20(19.0 \%)$ \\
\hline Partial $(<90 \%)$ & $23(22.0 \%)$ \\
\hline \multicolumn{2}{|l|}{ Occlusion rate at last follow-up } \\
\hline Complete $(100 \%)$ & $74(70.5 \%)$ \\
\hline Near-complete (90\%-99\%) & $17(16.2 \%)$ \\
\hline Partial (<90\%) & $14(13.3 \%)$ \\
\hline Adjunctive coil & $35(33.3 \%)$ \\
\hline Retreatment & $5(5.5 \%)$ \\
\hline \multicolumn{2}{|l|}{ Clinical outcome } \\
\hline \multicolumn{2}{|l|}{ Posttreatment mRS } \\
\hline $0-2$ & $84(94.4 \%)$ \\
\hline $3-5$ & $5(5.6 \%)$ \\
\hline 6 (death) & $0(0 \%)$ \\
\hline \multicolumn{2}{|l|}{ mRS at last follow-up } \\
\hline Improved & $16(18.0 \%)$ \\
\hline No change & $73(82.0 \%)$ \\
\hline Worsened & $0(0 \%)$ \\
\hline \multicolumn{2}{|l|}{ Neurologic complications } \\
\hline Thromboembolic & $40(44.0 \%)$ \\
\hline Symptomatic & $6(6.6 \%)$ \\
\hline Hemorrhagic & $3(3.3 \%)$ \\
\hline Symptomatic & $0(0 \%)$ \\
\hline Symptomatic cranial nerve compression & $1(1.1 \%)$ \\
\hline \multicolumn{2}{|l|}{ Long-term outcome } \\
\hline Rupture of aneurysm at follow-up & $0(0 \%)$ \\
\hline Compression improved at follow-up & $10(37.0 \%)$ \\
\hline Permanent neurologic complication & $0(0 \%)$ \\
\hline Permanent neurologic death & $0(0 \%)$ \\
\hline
\end{tabular}

follow-up period. The mortality rate was $0 \%$, the postprocedural morbidity rate was $7.7 \%$, and the permanent morbidity rate was $0 \%$ (Table 2).

\section{Predictor of Incomplete Occlusion}

The following factors were tested as predictors of aneurysm occlusion: age, sex, current smoker/nonsmoker, aneurysm type (saccular or fusiform), complications, maximum dome diameter of the aneurysm, neck diameter, aneurysm height, dome/ neck ratio, ASPECTS ratio, adjunctive coil usage, presence of aneurysms with the branching artery from the dome, and the classification of the saccular aneurysm. By means of a univariable analysis, age (older than 60 years, $P=.002$ ), fusiform aneurysms $(P=.012)$, aneurysms with the branching artery from the dome $(P<.001)$, and outer convexity type $(P<.001)$ were associated with significantly higher rates of incomplete occlusion at the last follow-up (Online Table 1). 
Table 3: Multivariable regression analysis of predictors for incomplete occlusion at last follow-up overall ${ }^{\mathrm{a}}$

\begin{tabular}{lccc}
\hline & OR & $95 \% \mathrm{CI}$ & $P$ Value \\
\hline Age ( $\geq 60$ years) & 5.70 & $1.99-19.5$ & .001 \\
Branching artery from dome & 10.56 & $2.36-63.2$ & .002 \\
Fusiform & 10.23 & $1.77-86.3$ & .009 \\
Type & & & \\
OC/IC & 30.3 & $4.96-595$ & $<.001$ \\
OC/LW & 9.71 & $2.45-52.0$ & .001 \\
LW/IC & 3.12 & $0.31-70.4$ & .34 \\
\hline
\end{tabular}

Note:-OC indicates outer convexity-type saccular aneurysm; IC, inner convexity-type saccular aneurysm; LW, lateral wall-type saccular aneurysm.

${ }^{a} n=105$; complete occlusion, 74; incomplete occlusion, 31. Significant predictors of incomplete occlusion include age older than 60 years, aneurysms with the branching artery from the dome, fusiform aneurysm, and outer convexity type.

Table 4: Multivariable regression analysis for incomplete occlusion using outer convexity type and aneurysms with a branching artery

\begin{tabular}{lccc}
\hline \multicolumn{1}{c}{ Parameter } & OR & $95 \% \mathrm{Cl}$ & $\boldsymbol{P}$ Value \\
\hline Outer convexity type (+) and branch (+) & 162 & $21.5-3587$ & $<.001$ \\
Outer convexity type (+) and branch (-) & 16.6 & $4.54-81.2$ & $<.001$ \\
Outer convexity type (-) and branch (+) & 9 & $1-73.2$ & .05 \\
Outer convexity type (-) and branch (-) & 1 & - & - \\
\hline
\end{tabular}

Note:-Branch indicates aneurysm with branching artery from dome; -, not applicable.

The significant predictors of incomplete occlusion at the last follow-up in the univariable analysis were further analyzed with a multivariable logistic regression. Age (older than 60 years; OR, 5.70; 95\% CI, 1.99-19.5; $P=.001)$, aneurysms with the branching artery from the dome (OR, 10.56; 95\% CI, 2.36-63.2; $P=.002)$, fusiform aneurysms (OR, 10.23; 95\% CI, 1.77-86.3; $P=.009)$, and outer convexity-type saccular aneurysms (versus inner convexity type: OR, 30.3; 95\% CI, 4.96-595; $P<.001$; versus lateral wall type: OR, 9.71; 95\% CI, 2.45-52.0; $P=.001$ ) were independently associated with a higher rate of incomplete occlusion at the last followup (Table 3). The number of each occlusion status per aneurysm type is shown in Online Table 2.

Among the 16 aneurysms with a branching artery from the dome, 10 aneurysms were the outer convexity type. Among the 35 outer convexity-type aneurysms, 10 aneurysms had the branching artery from the dome. Although multivariable logistic regression revealed that outer convexity-type and aneurysms with the branching artery from the dome were independent predictors of incomplete occlusion, there is a possible interaction between these 2 factors; therefore, further analysis was performed (Table 4). On the basis of double-negative aneurysms as a reference, aneurysms of the outer convexity type with the branching artery from the dome (OR, 162; 95\% CI, 21.5-3587; $P<.001$ ) were most susceptible to becoming an incomplete occlusion, followed by outer convexity-type aneurysms without the branching artery from the dome (OR, 16.6; 95\% CI, 4.54-81.2; $P<.001$ ) and non-outer convexity-type aneurysms with the branching artery from the dome (OR, 9.0; 95\% CI, 1.0-73.2; $P=.05$ ).

\section{Predictor of Bad Clinical Outcomes}

The posttreatment mRS was 0-2 in 94.4\% (84/89) of procedures and $3-5$ in $5.6 \%(5 / 89)$. The complications of deteriorated $\mathrm{mRS}$ included symptomatic thromboembolic strokes and newly appearing cranial nerve neuropathy due to thrombosing aneurysms. No major thromboembolic strokes occurred, and all patients were improved at 6-month follow-up. The follow-up mRS score was improved in $18 \%(16 / 89)$ and showed no change in $82 \%(73 / 89)$. These improvements included not only symptomatic thromboembolic strokes but also cranial nerve neuropathy caused by compression due to large/giant aneurysms. The mRS at the final follow-up was $0-2$ in all patients. The permanent neurologic complication rate was $0 \%$, and the permanent neurologic death was $0 \%$. In the long-term follow-up, no aneurysms were ruptured despite incomplete occlusion (Table 2).

\section{DISCUSSION}

In this study, we assessed predictors of incomplete occlusion and clinical outcome on the basis of high-followup-rate data. Several factors affecting complete/incomplete occlusion rates were previously reported (Online Table 3). ${ }^{10-13,15,16,21-26}$ However, these previous reports disagree about these predictors due to the limited analysis of confounding factors for each candidate predictor and an insufficient follow-up rate for incomplete occlusion cases. Additionally, the same morphologic index based on coil embolization was used in these analyses, even though the PED and coil embolization use different mechanisms to treat aneurysms. ${ }^{11,17}$

In the present study, we included previously reported factors as much as possible to assess the possibility of confounding factors. Additionally, we added the type of saccular aneurysm based on the location of the neck of the aneurysm against the arterial curvature as a morphologic factor. This new classification indirectly reflects the $\mathrm{MCR}$, which is the major index of the occlusion mechanism of $\mathrm{PED}^{18-20}$ and was reported to correlate with complete occlusion. ${ }^{18,19}$

On the basis of our multivariable regression analysis, in addition to age (older than 60 years; OR, 5.70; $P=.001$ ), fusiform aneurysms (OR, 10.23; $P=.009$ ), and aneurysms with the branching artery from the dome $(\mathrm{OR}, 10.56 ; P=.002)$, outer convexitytype saccular aneurysms (versus inner convexity type: OR, 30.3; $P<.001$; versus lateral wall type: $\mathrm{OR}, 9.71 ; P=.001$ ) were independently associated with a higher rate of incomplete occlusion at the last follow-up. Further analysis found an interaction between outer convexity-type aneurysms and aneurysms with the branching artery from the dome and that this interaction (OR, 162; $P<.001$ ) was most susceptible to becoming an incomplete occlusion, followed by outer convexity-type aneurysms without the branching artery from the dome (OR, 16.6; $P<.001)$ and nonouter convexity-type aneurysms with the branching artery from the dome (OR, 9.0; $P=.05$ ).

Our study is based on a single-center consecutive retrospective cohort. Among patients, 96.7\% (89/92) had DSA at 6 months after treatment. The long-term imaging follow-up rate for aneurysms with incomplete occlusion at 6 months was 95.3\% (41/43), and the median length of imaging follow-up for patients with 
incomplete occlusion at 6-month DSA was 27.5 months (range, 10-54 months). Each factor affecting our findings is discussed below.

\section{Predictors of Aneurysm Occlusion}

Type of Neck Location Related to Variation in Occlusion Rates. No previous report has proposed our saccular aneurysm classification with regard to the PED. The advantage of this classification is that it is simple and needs minimal, if any, software or calculations.

According to the mechanisms of aneurysm occlusion by PED previously reported, ${ }^{18-20,27-29}$ hemodynamics ${ }^{30-36}$ and endothelialization $^{29,37-41}$ are key factors and MCR and porosity are key indices for successful PED treatment. Our classification based on the curvature of the parent artery indirectly reflects the MCR and flow dynamics around the neck of the aneurysm and relates to the aneurysmal occlusion. MCR and porosity are the major indices of the occlusion mechanism of the PED and inverses of each other. ${ }^{18-20,37-39,42}$ The MCR is the portion of the ostium of the aneurysm covered by the metal of the flow diverter. ${ }^{20}$ In general, devices with a higher MCR provide a better scaffold for endothelialization. ${ }^{39-41}$

Two studies ${ }^{18,19}$ reported that the local metal coverage of the stent at the aneurysmal neck correlates with the occlusion of the aneurysm; a 35\% metal coverage at the neck predicted $>95 \%$ angiographic aneurysm occlusion with a specificity of $100 \%$ and sensitivity of $53.8 \%$. The PED is designed to have an MCR of $30 \%$. However, the MCR will change with the angle of the PED. Wang and Yuan ${ }^{18}$ reported the relationship between the MCR and the bending angle of the PED, showing that the MCR could range from $19 \%$ to $63 \%$, depending on the angle. Additionally, the MCR would become lower, and the porosity, higher in the outer convexity compared with their values in the inner concavity of the curvature of the parent artery. ${ }^{20,42-44}$ On the basis of those previous studies, we estimated that the local MCR around the neck of the aneurysm in the outer convexity type is $<30 \%$. We estimated the MCR to be $>35 \%$ for the inner convexity type and lateral wall type, though the MCR tends to be higher for the inner convexity. ${ }^{43,44}$ Therefore, our new classification of saccular aneurysms indirectly reflects the MCR around the aneurysmal neck and has an effect on the occlusion rate.

A neck location with outer convexity is also disadvantageous for PED treatment from the viewpoint of hemodynamics. From a computational fluid dynamics analysis, successful flow diversion depends on the following: 1) the flow resistance force of the flow diverter to decrease the flow velocity magnitude, ${ }^{30}$ 2) decreased jet flow into the aneurysm, ${ }^{31}$ 3) the aneurysm neck geometry, ${ }^{31}$ and 4) the patient-specific inflow threshold ${ }^{32}$ and other parameters such as the inflow rate, aneurysmal velocity reduction, and so forth. ${ }^{33}$ The flow velocity is faster at the outer convex side of a curved vessel than at the inner concave side, and the flow vector is toward the aneurysm in the outer convexity type. ${ }^{34,35}$ Therefore, the flow velocity magnitude and the jet flow into the aneurysm are higher in the outer convexity type than in other types of saccular aneurysms.

According to a computational fluid dynamics analysis of flow diveters, ${ }^{36}$ the velocity magnitude of the inflow stream of the aneurysm sac and the inflow volume rate increase as the curvature of the parent artery increases and are higher if the curvature angle is large after the flow-diverter placement. ${ }^{36}$ That study provides a theoretic explanation for why the outer convexity type resists complete occlusion compared with inner convexity and lateral wall types.

An overlapped flow-diverter placement was reported to be effective in decreasing the inflow volume rate, to overcome the possibility of incomplete occlusion in the outer convexity type. ${ }^{36}$ Technical manipulation is also recommended, such as a dynamic push-pull technique over the aneurysm orifice, which enhances the intended flow diversion, to compensate for the low MCR with the outer convexity type. ${ }^{45}$

\section{Age-Related Variation of Occlusion Rates}

Our data also showed that older age was one of the predictor of incomplete occlusion, consistent with a previous report. ${ }^{10}$

The mechanism of occlusion in PED-treated aneurysms, as mentioned above, could account for why older age was a predictor. The migration of endothelial cells slows with age, ${ }^{46}$ slowing endothelialization of the PED. Furthermore, atherosclerosis, which is also more common in older patients, could also contribute because the irregular shape of the endoluminal surface of the artery could form a gap between the endoluminal surface of the artery and the $\mathrm{PED}$, resulting in an endoleak to the aneurysm through the nonendothelialized area. ${ }^{11}$

\section{Branch-Related Variations in Occlusion Rates}

Aneurysms with the branching artery from the dome being a solid predictor of incomplete occlusion is consistent with several reports. ${ }^{22-26}$ The ophthalmic artery, posterior communicating artery, and anterior choroidal artery were all relevant in our series. In cases of aneurysms with the branching artery from the dome, when the branch has blood demand, blood flow through the PED inhibits endothelialization, resulting in remnant flow to the aneurysm and incomplete occlusion. Notably, this factor was independent from and had interaction with the type of neck location.

\section{Fusiform or Saccular Variation in Occlusion Rates}

Our data also showed that fusiform aneurysms were a significant predictor of incomplete occlusion compared with saccular aneurysms, consistent with previous studies. ${ }^{11,16,25}$ The reason could be the occlusion mechanisms of the PED. In the case of fusiform aneurysms, a wider surface area of the PED is exposed to the aneurysm without support by the vessel wall compared with saccular aneurysms. These areas are more likely to be devoid of endothelialization. ${ }^{47}$

\section{Predictor of Clinical Outcome}

We also assessed predictors of the clinical outcome; however, no ruptures of aneurysms were observed in the follow-up periods. These findings indicate that aneurysms treated with the PED are clinically safe and stable, even with aneurysm remnants, as reported previously. $^{12}$

\section{Limitations}

The limitations of the study include its retrospective design with all the inherent biases associated with such a study design. Although this study is from a single center and thus warranted a unified treatment procedure, antiplatelet regimen, and follow-up imaging protocol, the retrospective nature of this study and 
analysis from a single center introduce sampling bias and possibly limit external validity.

Twelve aneurysms with incomplete occlusion had follow-ups of $<2$ years. The possibility for these aneurysms to occlude thereafter could affect the results because complete aneurysmal occlusion is expected to occur up to 2 years post-PED deployment. ${ }^{48}$

Finally, because some patients had multiple aneurysms, we performed multiple logistic regression using generalized estimating equations to consider intrapatient correlations.

\section{CONCLUSIONS}

In this study, on the basis of high follow-up data, we analyzed the angiographic and clinical outcomes of unruptured ICA aneurysms after PED treatment. Clinically, ICA aneurysms were safe without rupture in the follow-up period, even with aneurysm remnants. Angiographically, in addition to age, fusiform aneurysms, and aneurysms with the branching artery from the dome, the outer convexitytype of saccular aneurysm was a predictor of incomplete occlusion.

\section{ACKNOWLEDGMENTS}

We are grateful to Yuuji Naramoto, MD, Rikuo Nishii, MD, and Yasuhiro Yamamoto, MD, at the Department of Neurosurgery, Kobe City Medical Center General Hospital, Kobe, for collecting some of the data. We thank Dr Peter Karagiannis and Sofia Science Writing for critical reading and proofreading of the manuscript. We are grateful to Chisato Miyakoshi, MD, MSc, at the Department of Pediatrics, Kobe City Medical Center General Hospital, Kobe, for the consultation on statistics analysis.

Disclosures: Nobuyuki Sakai-UNRELATED: Grants/Grants Pending: Medtronic, NeuroVasc, Terumo; Payment for Lectures Including Service on Speakers Bureaus: ASAHI INTEC, Biomedical Solutions, Johnson \& Johnson, Medtronic, Stryker, Terumo.

\section{REFERENCES}

1. Fiorella D, Woo HH, Albuquerque FC, et al. Definitive reconstruction of circumferential, fusiform intracranial aneurysms with the Pipeline Embolization Device. Neurosurgery 2008;62:1115-20; discussion 1120-21 CrossRef Medline

2. Becske T, Kallmes DF, Saatci I, et al. Pipeline for uncoilable or failed aneurysms: results from a multicenter clinical trial. Radiology 2013;267:858-68 CrossRef Medline

3. Becske T, Brinjikji W, Potts MB, et al. Long-term clinical and angiographic outcomes following Pipeline Embolization Device treatment of complex internal carotid artery aneurysms: five-year results of the Pipeline for Uncoilable or Failed Aneurysms trial. Neurosurgery 2017;80:40-48 CrossRef Medline

4. Kallmes DF, Hanel R, Lopes D, et al. International retrospective study of the Pipeline Embolization Device: a multicenter aneurysm treatment study. AJNR Am J Neuroradiol 2015;36:108-15 CrossRef Medline

5. Becske T, Potts MB, Shapiro M, et al. Pipeline for Uncoilable or Failed Aneurysms: 3-year follow-up results. J Neurosurg 2017;127:81-88 CrossRef Medline

6. Nelson PK, Lylyk P, Szikora I, et al. The Pipeline Embolization Device for the intracranial treatment of aneurysms trial. AJNR Am J Neuroradiol 2011;32:34-40 CrossRef

7. Lylyk P, Miranda C, Ceratto R, et al. Curative endovascular reconstruction of cerebral aneurysms with the Pipeline Embolization
Device: the Buenos Aires experience. Neurosurgery 2009;64:632-42 CrossRef Medline

8. Kallmes DF, Brinjikji W, Cekirge S, et al. Safety and efficacy of the Pipeline Embolization Device for treatment of intracranial aneurysms: a pooled analysis of 3 large studies. J Neurosurg 2017;127:77580 CrossRef Medline

9. Munich SA, Cress MC, Rangel-Castilla L, et al. Neck remnants and the risk of aneurysm rupture after endovascular treatment with coiling or stent-assisted coiling: much ado about nothing? Clin Neurosurg 2019;84:421-47 CrossRef Medline

10. Adeeb N, Moore JM, Wirtz M, et al. Predictors of incomplete occlusion following Pipeline embolization of intracranial aneurysms: is it less effective in older patients? AJNR Am J Neuroradiol 2017;38:2295300 CrossRef Medline

11. Shapiro M, Becske T, Nelson PK. Learning from failure: persistence of aneurysms following Pipeline embolization. J Neurosurg 2017;126:578-85 CrossRef Medline

12. Madaelil TP, Grossberg JA, Howard BM, et al. Aneurysm remnants after flow diversion: clinical and angiographic outcomes. AJNR Am J Neuroradiol 2019;40:694-98 CrossRef Medline

13. Liang B, Lesley WS, Robinson TM, et al. Off-label application of Pipeline Embolization Device for intracranial aneurysms. Neurointervention 2019;14:116-24 CrossRef Medline

14. Zhang Y, Liang F, Zhang Y, et al. Exploring the feasibility of Pipeline Embolization Device compared with stent-assisted coiling to treat non-saccular, unruptured, intradural vertebral artery aneurysms. Front Neurol 2019;10:275 CrossRefMedline

15. O'Kelly CJ, Spears J, Chow M, et al. Canadian experience with the Pipeline Embolization Device for repair of unruptured intracranial aneurysms. AJNR Am J Neuroradiol 2013;34:381-87 CrossRef Medline

16. Jabbour P, Chalouhi N, Tjoumakaris S, et al. The Pipeline Embolization Device: learning curve and predictors of complications and aneurysm obliteration. Neurosurgery 2013;73:113-20 CrossRef Medline

17. Li Y, Kim J, Ahmed A. Effect of aneurysm morphologic parameters on occlusion rates following Pipeline embolization. Clin Neurol Neurosurg 2019;183:105395 CrossRef Medline

18. Wang K, Yuan S. Actual metal coverage at the neck is critical for flow-diverting stents in treating intracranial aneurysms. AJNR Am J Neuroradiol 2013;34:31-32 CrossRef Medline

19. Wang K, Huang Q, Hong B, et al. Correlation of aneurysm occlusion with actual metal coverage at neck after implantation of flowdiverting stent in rabbit models. Neuroradiology 2012;54:607-13 CrossRef Medline

20. Jou LD, Chintalapani G, Mawad ME. Metal coverage ratio of Pipeline Embolization Device for treatment of unruptured aneurysms: reality check. Interv Neuroradiol 2016;22:42-48 CrossRef Medline

21. Brasiliense LBC, Aguilar-Salinas P, Miller DA, et al. Analysis of predictors and probability of aneurysm occlusion in the internal carotid artery after treatment with Pipeline Embolization Device. World Neurosurg 2017;107:641-48 CrossRef Medline

22. Puffer RC, Lanzino G, Kallmes D, et al. Patency of the ophthalmic artery after flow diversion treatment of paraclinoid aneurysms. $J$ Neurosurg 2012;116:892-96 CrossRef Medline

23. Raz E, Shapiro M, Becske T, et al. Anterior choroidal artery patency and clinical follow-up after coverage with the Pipeline Embolization Device. AJNR Am J Neuroradiol 2015;36:937-42 CrossRef Medline

24. Vedantam A, Rao VY, Shaltoni HM, et al. Incidence and clinical implications of carotid branch occlusion following treatment of internal carotid artery aneurysms with the Pipeline Embolization Device. Neurosurgery 2015;76:173-78 CrossRef Medline

25. Moshayedi H, Omofoye OA, Yap E, et al. Factors affecting the obliteration rate of intracranial aneurysms treated with a single Pipeline Embolization Device. World Neurosurg 2017;104:2-5 CrossRef Medline 
26. Volker M, Anastasios M, Jan B, al. Treatment of intracranial aneurysms with the Pipeline Embolization Device only: a single center experience. Neurointervention 2018;13;32-40 CrossRef Medline

27. Chua MM, Silveira L, Moore J, et al. Flow diversion for treatment of intracranial aneurysms: mechanism and implications. Ann Neurol 2019;85:793-800 CrossRef Medline

28. Schneiders JJ, VanBavel E, Majoie CB, et al. A flow-diverting stent is not a pressure-diverting stent. AJNR Am J Neuroradiol 2013;34:1-4 CrossRef Medline

29. Kadirvel R, Ding YH, Dai D, et al. Cellular mechanisms of aneurysm occlusion after treatment with a flow diverter. Radiology 2014;270:394-99 CrossRef Medline

30. Zhang Y, Chong W, Qian Y. Investigation of intracranial aneurysm hemodynamics following flow diverter stent treatment. Med Eng Phys 2013;35:608-15 CrossRef Medline

31. Chong W, Zhang Y, Qian Y, et al. Computational hemodynamics analysis of intracranial aneurysms treated with flow diverters: correlation with clinical outcomes. AJNR Am J Neuroradiol 2014;35:13642 CrossRef Medline

32. Berg P, Saalfeld S, Janiga G, et al. Virtual stenting of intracranial aneurysms: a pilot study for the prediction of treatment success based on hemodynamic simulations. Int J Artif Organs 2018;41:698705 CrossRef Medline

33. Paliwal N, Damiano RJ, Davies JM, et al. Association between hemodynamic modifications and clinical outcome of intracranial aneurysms treated using flow diverters. Proc SPIE Int Soc Opt Eng 2017;10135:101352F CrossRef Medline

34. Kalpakli A. Experimental study of turbulent flows through pipe bends. KTH Royal Institute of Technology 2012;6-29

35. van Wyk S, Wittberg LP, Bulusu KV, et al. Non-Newtonian perspectives on pulsatile blood-analog flows in a $180^{\circ}$ curved artery model. Physics of Fluids 2015;27:71901 CrossRef

36. Xu J, Wu Z, Yu Y, et al. Combined effects of flow diverting strategies and parent artery curvature on aneurysmal hemodynamics: a CFD study. PLoS One 2015;10:e0138648 CrossRef Medline

37. Marosfoi M, Langan ET, Strittmatter L, et al. In situ tissue engineering: endothelial growth patterns as a function of flow diverter design. J Neurointerv Surg 2017;9:994-98 CrossRef Medline
38. Sadasivan C, Cesar L, Seong J, et al. An original flow diversion device for the treatment of intracranial aneurysms: evaluation in the rabbit elastase-induced model. Stroke 2009;40:952-58 CrossRef Medline

39. Panchendrabose K, Muram S, Mitha AP. Promoting endothelialization of flow-diverting stents: a review. J Neurointerv Surg 2020 June 2. [Epub ahead of print] CrossRef Medline

40. Raymond J, Darsaut TE, Makoyeva A, et al. Endovascular treatment with flow diverters may fail to occlude experimental bifurcation aneurysms. Neuroradiology 2013;55:1355-63 CrossRef Medline

41. Hong B, Wang K, Huang Q, et al. Effects of metal coverage rate of flow diversion device on neointimal growth at side branch ostium and stented artery: an animal experiment in rabbit abdominal aorta. Neuroradiology 2012;54:849-55 CrossRef Medline

42. Ma D, Dumont TM, Kosukegawa H, et al. High-Fidelity Virtual Stenting (HiFiVS) for intracranial aneurysm flow diversion: in vitro and in silico. Ann Biomed Eng 2013;41:2143-56 CrossRef Medline

43. Bing F, Darsaut TE, Salazkin I, et al. Stents and flow diverters in the treatment of aneurysms: device deformation in vivo may alter porosity and impact efficacy. Neuroradiology 2013;55:85-92 CrossRef Medline

44. Aurboonyawat T, Blanc R, Schmidt P, et al. An in vitro study of Silk stent morphology. Neuroradiology 2011;53:659-67 CrossRef Medline

45. Ma D, Xiang J, Choi $\mathrm{H}$, et al. Enhanced aneurysmal flow diversion using a dynamic push-pull technique: an experimental and modeling study. AJNR Am J Neuroradiol 2014;35:1779-85 CrossRef Medline

46. Lähteenvuo J, Rosenzweig A. Effects of aging on angiogenesis. Circ Res 2012;110:1252-63 CrossRef Medline

47. Szikora I, Turányi E, Marosfoi M. Evolution of flow-diverter endothelialization and thrombus organization in giant fusiform aneurysms after flow diversion: a histopathologic study. AJNR Am J Neuroradiol 2015;36:1716-20 CrossRef Medline

48. Gupta R, Ogilvy CS, Moore JM, et al. Proposal of a follow-up imaging strategy following Pipeline flow diversion treatment of intracranial aneurysms. J Neurosurg 2018;131:32-39 CrossRef Medline 